\title{
Fracture Initiation and Fragmentation in Chemically Tempered Glass
}

\author{
Rajan Tandon and S. Jill Glass \\ Materials Reliability Department \\ Materials Science and Engineering Center \\ Sandia National Laboratories, NM 87185 USA \\ Corresponding Author: \\ Rajan Tandon \\ Materials Reliability Department \\ Materials Science and Engineering Center \\ Sandia National Laboratories, NM 87185 USA \\ rtandon@sandia.gov, Phone: 0015058441187
}




\begin{abstract}
Residual stress profiles are introduced in an alumino-silicate glass using ion-exchange. Due to a high central tension in these glasses, fracture is often followed by fragmentation. Fracture was initiated by loading the glasses with a Vicker's indenter, either monotonically to fracture, or loading to a fixed load, and then unloading. Fracture loads in the load-unload method were $1 / 2-1 / 3$ of that during monotonic loading. A qualitative explanation of this phenomenon is proposed by extending an analysis of stresses at the indentation site. The process of fragmentation under indentation, crack propagation and repeated multiple branching, is described. The fragmentation behavior when fracture is initiated in biaxial loading is different: a single crack creates numerous branches, which then propagate without further branching. This process is explained in terms of the stress distribution in the sample prior to fracture initiation. The implications for practical instances where fragmentation is important are discussed.
\end{abstract}

Keywords: Fragmentation, ion-exchanged glass, stress, indentation, fracture 


\section{INTRODUCTION}

Fragmentation is a dynamic process in which rapid crack branching or multiple crack initiation and propagation occurs during fracture of a highly strained material. This process produces particles of the material that are significantly smaller than the original dimensions. The fragmentation process in brittle materials occurs in several instances of practical importance such as fracture of windows in structures, in ceramic armor, and in "dirty" bomb particle generation and dispersal. The conditions for onset of fragmentation, and the size and shape distribution of the resultant particles are of interest for such safety and security applications. For a recent review on this subject, see Grady [1].

Glasses with compressive surface stresses find use in architectural, automotive and consumer electronics applications. As fracture in brittle materials usually initiates from surface flaws, the compressive stress inhibits crack initiation and propagation, leading to increased strength. These effects have been observed for thermally and chemically tempered (subsequently referred to as tempered and ion-exchanged respectively) glasses [2-4], and for oxide [5-6] and non-oxide ceramics [7]. As residual stresses are self-compensating, there is a zone of tension, usually beneath the compressive surface. If a crack penetrates to this tensile region, fragmentation can occur, and this principle is utilized to make automobile window glass safer. For tempered glasses, the role of the internal tensile stress in causing fragmentation is well known [8-13]. In these studies, it was assumed that the central tension was the dominant effect in fragmentation, and its value was correlated to the number of fragments. Assuming that the fragments were parallelepiped, a relationship describing the number of fragments as being proportional to central tension raised to the fourth power was derived and experimentally validated [8,9]. Warren [10] utilized empirical correlations to describe the case where not all of the strain energy is consumed during fragmentation. He also questioned the assumption that the fragments were parallelepiped, asserting that fragments could have aspect ratios of up to 10. This has been confirmed in our work [11] on thermally tempered glass. We find that fragmentation induced by a diamond punch in plates of tempered glass proceeds mainly by the propagation of long cracks from the punch site. Moisture induced time-dependent crack pop-in, almost perpendicular to the main crack (secondary cracks), determines the average fragment size, as there is little macroscopic branching (or forking) from the main cracks. Acloque and Morain [12] clearly showed the influence of environment and time on secondary cracking. 
They showed that secondary cracking continually increased for the first thousand seconds after fragmentation initiation. The number of secondary cracks also increased with increasing humidity. Akeyoshi and Kanai's [13] data show that the fragment size-central tension relationship cannot be described by the fourth-power relationship, and that for the same central tension the particle size decreases as the glass thickness increases. Aratani et. al. [14] used a high speed camera to determine the effect of shock waves on fracture propagation, and residual stress on crack velocity. They showed that there was a "peculiar point", a location in the sample where the fragment size distribution decreased, and attributed this to the interaction of the shock waves reflected from the sample edge with the crack front. Takahashi [15] studied impact fracture of edge-supported samples of zone tempered glass under high speed imaging, measured the terminal crack velocities, and concluded that there was a weak correlation between residual compression and crack velocity, with higher compression leading to higher velocity. Nielsen et al. [16] initiated fracture in tempered glass using a diamond drill and captured the process details using high-speed digital cameras. From these pictures, they determined the average speed of the fracture front to be $1470 \mathrm{~m} / \mathrm{s}$, close to terminal velocity of crack propagation in glass. The phenomenon of cracking in the compressive region that started near the surface and ran to the center of the sample was reported. This was hypothesized to occur because of a slight expansion in the region originally under compression, due to cracking in the central tensile region. This also pointed out the existence of a micro-scale crack bridging effect that keeps the fragments of the glass together even after fracture.

Less attention has been paid to the fragmentation process for ion-exchanged glasses, but with the advent of handheld devices using this material, consumer safety entails that fragmentation be avoided. Zijlstra and Burggraaf [17] described fracture and fragmentation of ion-exchanged glass under flexure loading induced by a free-falling steel projectile on a simply supported glass plate. They presented an approach to reduce the sharpness of fragments of ion-exchanged glass. They found a powdering effect at the edges of the fragments when the maximum in the compressive stress profile was shifted approximately $40 \mathrm{~m}$ below the surface, and the difference between the stress maximum and the surface stress was $>147 \mathrm{MPa}$. This powdering effect rendered the fragments less sharp. Although they clearly pointed out conditions to achieve the powdering phenomena, they did not present an analysis or physical insight into their results. Hill and Donald [18] described the preparation and properties of a lithium magnesium alumino-silicate glasses. The lithium in this glass structure is exchanged by sodium ions (in a molten 
salt solution), leading to compressive surface stresses. Unusual stress profiles, with the surface being in tension due to extreme stress relaxation, were reported. They observed fragmentation of this glass after biaxial flexural loading, with the higher strength samples possessing smaller fragments. Bouyne and Gaume [19] developed an approximate stress-intensity factor based on the stored elastic strain energy in the core, and calculated the shape factor in the stress intensity factor expressions using finite element analysis. They predicted that to obtain identical levels of fragmentation, the tensile stress in ion-exchanged glass could be significantly less than in thermally tempered glass. They also measured the number of fragments in a variety of ion-exchanged and tempered glass specimens, and found that when plotted against the approximate stress intensity factor, all fragment numbers fell on the same curve. This indicates that the same factor controls fragmentation, independent of glass thickness and stress profile. They assert that the parameter controlling fragmentation is the elastic strain energy in the tensile core of the glass. Morris et al. [20] describe radial crack initiation under a Vickers indenter on the same glass composition that is of interest here.but For short exchange times, they observed an increase in threshold load for crack initiation under load-unload conditions with increasing exchange times, and proposed a fracture-mechanics model to predict threshold loads for crack initiation.

The motivation of the present work was to improve the understanding of the fragmentation of ionexchanged glass, and the results of the study will help identify processing conditions for the glass, (viz., ionexchange time, temperature, and sample thickness), and the loading conditions needed to produce a desired combination of strength, fragmentation, and reliability. Reliability here encompasses the repeatability and predictability of the fragmentation process in addition to the usual mechanical strength aspects. We will compare the fragmentation induced using a sharp tipped diamond indenter on a fully-supported sample to that obtained during a biaxial flexure test. An analysis of stress distributions at an indentation site is extended to better interpret our results. It is demonstrated that for static and quasi-static loading conditions, the size and shape of fragments formed are extremely sensitive to the stress state in the material, which is a combination of the applied and the residual (ionexchange) stress. The implications of these observations for practical applications are briefly considered. 


\section{EXPERIMENTAL PROCEDURES}

\subsection{Materials and Exchange Treatment}

The material studied was an alumino-silicate glass (Corning Code 0317, Corning Inc., NY 14831). The composition of the glass (in wt\%) is: $61.9 \% \mathrm{SiO}_{2}, 16.5 \% \mathrm{Al}_{2} \mathrm{O}_{3}, 11.9 \% \mathrm{Na}_{2} \mathrm{O}, 3.3 \% \mathrm{MgO}, 3.4 \% \mathrm{~K}_{2} \mathrm{O}, 1.8 \% \mathrm{Li}_{2} \mathrm{O}$, $0.7 \% \mathrm{TiO}_{2}, 0.4 \% \mathrm{CaO}$ and a trace of $\mathrm{Fe}_{2} \mathrm{O}_{3}$. Glass disks of diameter $25.4 \mathrm{~mm}$, and two different thicknesses $(1.8$ $\mathrm{mm}$, and $2.2 \mathrm{~mm}$ ) were used for this study. The results for the two thicknesses have many similar features, and are co-mingled in this report. Ion-exchange was used to incorporate the residual stress profiles by submerging glass samples in pure molten potassium nitrate. Because of a chemical potential difference, the $\mathrm{Na}^{+}$ions in the glass are released into the molten salt, and the $\mathrm{K}^{+}$ions replace them in the glass structure. Two different exchange temperatures, $450^{\circ} \mathrm{C}$ and $500^{\circ} \mathrm{C}$, were employed and the bath temperature was controlled to $\pm 2^{\circ} \mathrm{C}$. These temperatures are below the glass transition temperature ( strain point $=576^{\circ} \mathrm{C}$ ), and therefore the $\mathrm{K}^{+}$ions are not accommodated in the structure of the glass. The exchanged layer has a larger volume than the bulk, and this leads to the development of a surface compressive stress and a compensating tensile stress in the interior [17, 21]. The ion-exchange was conducted for time intervals of $3,6,12,24,48,96$ and 144 hours. The depth of the $\mathrm{K}^{+}$ion penetration into the glass is an important parameter as the extent of the compressive stress profile is determined by the exchange depth. This depth was measured on fragmented cross-sections of samples using electron microprobe analysis.

\subsection{Material Characterization: Central Tension}

The values of the compensating tensile stress in the bulk were obtained using the experimental approach described in Ref. 21. A white light source was viewed through a crossed polarizer and analyzer set to obtain extinction. The samples were then introduced such that the light beam passed along the disk diameter. The birefringence introduced due to the internal tension led to the extinction condition being disturbed, and a particular fringe color was observed in the eyepiece. A Soliel-Babinet compensator and additional quarter wave-plates were then introduced in the light path to re-obtain extinction. Knowing the retardation induced by the compensator-waveplate combination to attain extinction and the stress optic coefficient of the glass $(27.5 \mathrm{~nm} / \mathrm{cm} . \mathrm{MPa})$, the central tension value was calculated. For each thickness and exchange condition, the stress in 3-5 samples was measured. 
Measurement of compressive stress profiles in these highly ion-exchanged glasses were not accomplished: all attempts to section the caused fragmentation, and other approaches such as the physical removal of the outer sections followed by stress determination [22] are tedious. However, as will be shown in Sections 3, 5, the form of these stresses can be estimated from our other results, and previous work on soda-lime glasses [23].

\subsection{Fragmentation Experiments}

In preliminary tests, disks that were ion-exchanged for various times were loaded at indentation loads ranging from 100-200 N, unloaded, and examined for fracture. If fracture was not observed, the indentation load was increased until fracture was initiated. Disks were placed on an Instron load cell, and loaded with a Vickers indenter at a crosshead-speed of $0.1 \mathrm{~mm} / \mathrm{min}$. Two types of experiments were performed: In one, the load was increased monotonically until fracture of the sample occurred. Between 7-10 samples were fractured in this manner for each exchange time. Fracture was accompanied by a load-drop and fracture or fragmentation. In the second experiment (performed only on a limited number of samples), samples were loaded to a pre-selected value, and unloaded. If fracture did not occur during unloading, or within a two minute period after unloading, another site on the sample was loaded. In this manner, loads that were sufficiently high to cause fracture either during unloading, or soon thereafter were identified. The times to fracture for these samples were recorded.

Disks exchanged under various test conditions were subjected to ring-on-ring biaxial flexure tests. The diameters of the loading and support rings were $10 \mathrm{~mm}$ and $21 \mathrm{~mm}$ respectively. Tests were conducted in accordance with ASTM C1499, and the loading rate was $20 \mathrm{MPa}$. F. For each test condition, two to five samples

were fractured; however, because of the high strengths of the samples, fractures often did not occur from within the loading ring, but rather originated beneath the loading ring. Therefore, in some case, only one or two valid sample strengths could be obtained. In order to establish a baseline, the strengths of five un-exchanged glass disks were measured. In both indentation and biaxial tests, the disks were enveloped with tape to hold the fragments together, with a perforation made for the indenter to penetrate. 


\section{RESULTS:}

Table 1 lists the ion-exchange depths and central tension values for the $1.8 \mathrm{~mm}$ thick sample, at two different exchange temperatures, $450^{\circ}$ and $500^{\circ} \mathrm{C}$. The exchange depth increases with time and temperature. For longer exchange times (96 hrs.), the exchange thickness is $\sim 20 \%$ of the sample thickness, which approaches the norm for tempered glass $(\sim 22 \%)$. The tensile stress $\left(\sigma_{\mathrm{T}}\right)$ stored in the mid-section of the glass, however, is significantly greater $(\sim 140 \mathrm{MPa})$ than those typically observed in tempered glass (peak value $50-60 \mathrm{MPa}$ ). Measurements also confirm that for most exchange conditions this tensile stress profile is more or less uniform throughout the central region, as opposed to being parabolic for tempered glass. Hence the strain energy, from the tensile stresses alone in an ion exchanged body can be significantly higher than that in thermally tempered glass. The compressive stresses in the ion-exchange layer were not measured, but the strength results (in Fig. 4), and the known interplay between ion penetration and stress relaxation with increasing time of exchange [23] will be used in Section 5 to describe the possible compressive stress distribution.

The load to initiate fracture (and consequent fragmentation) during monotonically increasing load for a 1.8 $\mathrm{mm}$ thickness glass for various exchange times at $450^{\circ} \mathrm{C}$ is shown in Figure 1a. The individual failure loads, and the mean values for each case are shown. There is a large scatter in failure loads with the greatest scatter for the shorter exchange times. The mean value is highest for the 3 hour exchange, and is almost constant $(\sim 500 \mathrm{~N})$ for other exchange times. Fig. 1b shows the time to failure as a function of load for the experiments where similar samples (1.8 $\mathrm{mm}$ thick, $450^{\circ} \mathrm{C}$ exchange) were loaded to a peak load and unloaded. Loads required to cause fracture in this condition are between $1 / 2$ to $1 / 3$ of that during monotonic loading. The fracture load decreases with increasing time of ion-exchange. Also evident is a time-dependent crack initiation mechanism, probably moisture-enhanced faulting, like that noted by Lawn et al. [24] for a soda-lime glass. Several samples failed either during or immediately after unloading (time, $\mathrm{t}=0$ ). In Section 5, we will show that the stresses driving the cracks causing fragmentation in this loading mode increase during unloading, and are at a maximum on complete unload. This implies that the required loads to cause fracture for samples depicted as failing at time $\mathrm{t}=0$ are lower than the ones plotted in Fig. $1 \mathrm{~b}$. 
Fig. 2 is a montage of the fracture surface of a $2.2 \mathrm{~mm}$ thick sample exchanged for 24 hour at $450^{\circ} \mathrm{C}$, which fractured during indentation loading. The loading site is marked on the figure. The fracture surface reveals that a median crack popped in at the indentation, and propagated through the thickness. This crack then swept through the sample from left to right under the action of the tensile residual stresses. The black dashed line marks the first hackle for this crack. A mirror region beyond this branch is seen further to the right followed by mist and hackle. The mist region starts close to the center of the sample, and the mist and hackle spread out towards the surfaces of the sample. Further to the right but not shown, the hackle extends to the surfaces of the samples.,It ends in a macroscopic crack bifurcation event. The fact that mist formation starts near the center of the sample, and spreads outwards indicates that despite the tensile stress being uniform through-the-thickness, the stress intensity factor $\left(\mathrm{K}_{1}\right)$ on the travelling crack is highest at the center.

Fig. 3a-f show the typical fragmentation patterns (top view) from tests on the $1.8 \mathrm{~mm}$ thick samples exchanged at $500^{\circ} \mathrm{C}$. Based on the fracture surface observations, the patterns obtained may be described as follows: A median crack initiates under high loads from the bottom of the impression, and due to the tensile fields in the sample propagates through-the-thickness. This rectangular shaped crack fronts then propagate towards the edge of the samples under the tensile residual stress. For low internal tension values (=shorter exchange times), the crack may (Fig. 3b) or may not (Fig 3a) branch; however, as the tensile stress values increase ( $>45 \mathrm{MPa})$, multiple crack branching is observed. Often three or four branches are observed from each crack tip, and it is apparent that fragmentation is from the propagation of these cracks, and their branches throughout the sample. The initial fragments formed around the indentation are large (3b-e), but the fragment size reduces as crack fronts propagate towards the circumference of the sample. For extremely high values of tension (3f), almost uniform sized fragments, 1-2 $\mathrm{mm}$ in size are obtained. Similar features are apparent for other thickness samples, and for the lower ionexchange temperatures. Fig. $3 \mathrm{~g}$ shows a fragmented sample exchanged at $450^{\circ} \mathrm{C}$ for $12 \mathrm{hrs}$, thickness $=1.8 \mathrm{~mm}$. This sample has a central tension of $\sim 37 \mathrm{MPa}$, and its fragmentation behavior is slightly less severe than $6 \mathrm{hrs}$., $500^{\circ} \mathrm{C}$ $\left(\sigma_{\mathrm{t}}=45 \mathrm{MPa}, 3 \mathrm{~b}\right)$, but more severe than $3 \mathrm{hrs} ., 500^{\circ} \mathrm{C}\left(\sigma_{\mathrm{t}}=37 \mathrm{MPa}, 3 \mathrm{a}\right)$. This indicates that the central tension level is not the only determinant of fragmentation behavior, contrary to some prior assertions [8, 19]. 
The biaxial ring-on-ring strength results for various exchange times and sample thicknesses are shown in

Fig. 4. As the number of samples was limited, only the average values for the strength at each condition are plotted. For all exchange conditions, the strength is significantly higher than the base glass reference (exchange time, $\mathrm{t}=0$ ), highlighting the beneficial effects of surface compression on the strength. Using the baseline strength, and a fracture toughness of the material of $\sim 0.8 \mathrm{MPa} . \mathrm{m}^{1 / 2}$, the depth of the flaws likely to cause failure was calculated to be $8-10$ $\mathrm{m}$. The depth of exchange for the shortest exchange time ( $3 \mathrm{hrs}$.) ranges from $35-64 \mathrm{~m}$ (see Table 1). Therefore, it is likely that all the strength controlling flaws are fully enveloped by the compression layer. It is well known that the ion concentration profile will have a maximum at the surface and follow an error-function distribution in the interior of the sample [23]. Hence the highest values of strength are attained for $3 \mathrm{hr}$. exchange samples. Increasing the exchange times increases the ion-exchange depth, well-beyond the size of the strength controlling flaws, but it also leads to stress relaxation at and near the surface $[21,23]$. Hence the compressive stresses acting on the strength controlling flaws are reduced, leading to a lower value of strength.

The top-views of $1.8 \mathrm{~mm}$ thick samples exchanged at $500^{\circ} \mathrm{C}$, and fractured in biaxial flexure, for several exchange times are shown in Fig. 5a-g. Fig. 5a-c is the view of the entire $25.4 \mathrm{~mm}$ diameter disks, while 5d-f are magnified optical images of the area near to the fracture origin. The approximate location of the loading ring (on the far side) is marked by the dashed line in Fig. 5b. The high loads necessary to cause fracture lead to high contact stresses that cause local crushing under the contact ring. It is apparent that fragmentation behavior of these samples is quite different from similar materials broken in indentation loading. Not only is the visual appearance of fragmentation different, but the trend observed for indentation-fractured samples viz., smaller, more equi-sized fragments for longer exchange times, does not hold. Here it appears that the extent of fragmentation decreases slightly with increasing time of exchange, or as will be argued in Section 5, with decreasing strength of the material. Examining Fig. 5d, e, for $3 \mathrm{hr}$. and $96 \mathrm{hr}$. exchange sample, it is clear that a surface crack initiates at (a), and then creates multiple branches at its ends, marked (b) and (b). These branches propagate to the edges of the sample, largely without any further crack bifurcations, although secondary cracks (c), perpendicular to the main crack are visible (in Section 1, the presence of these secondary cracks on tempered glass surfaces was noted). Conversely, Fig. 5f for a longer $144 \mathrm{hr}$. exchange sample shows a large number of crack branches from the initial crack, but minimal secondary cracking. 


\section{ANALYSIS:}

To qualitatively understand observations of crack initiation on the stressed surfaces during indentation loading/unloading, a simple analytical model for indentation stresses, proposed by Yoffe [25], and further discussed by Cook and Pharr [26] is employed. Here the indentation stress field during any portion of the loading and unloading cycle is described as a sum of two components: the field from the load, $P$, acting on the surface of the solid, and the field from the mismatched elastic-plastic zone (the blister field), whose strength is characterized by the term $B$. It is noted that this analysis is for a conical indenter, i.e., edge and tip intensifications due to the use of a real Vickers tip are ignored. However, as observed in Ref. 26 for unstressed surfaces, and as will be shown here for the case of a surface stress, the analysis results are in qualitative agreement with experiments. The stresses in the spherical coordinate frame, $r, \theta, \phi$ in Fig 6a for a material with no surface stress (Poisson's ratio $=0.25)$ are $[25]$ :

$$
\begin{aligned}
\sigma_{r r} & =\frac{P}{4 \pi r^{2}}(1-7 \cos \theta)+\frac{B}{r^{3}}\left(19 \cos ^{2} \theta-7\right) \\
\sigma_{\theta \theta} & =\frac{P}{4 \pi r^{2}} \frac{\left(\cos ^{2} \theta\right)}{(1+\cos \theta)}-\frac{B}{r^{3}} \cos ^{2} \theta \\
\sigma_{\phi \phi} & =\frac{P}{4 \pi r^{2}}\left(\cos \theta-\frac{1}{(1+\cos \theta)}\right)+\frac{B}{r^{3}}\left(2-3 \cos ^{2} \theta\right) \\
\sigma_{r \theta} & =\frac{P}{4 \pi r^{2}} \frac{(\sin \theta \cos \theta)}{(1+\cos \theta)}-\frac{5 B}{r^{3}} \sin \theta \cos \theta
\end{aligned}
$$

During the loading and unloading cycle, the value of $\mathrm{P}$ in the above expressions, increases and then decreases, and is zero at complete unload. However, the value of B is fixed because of the geometrical selfsimilarity of the problem, and because the hardness of the material is invariant. Yoffe [25] was able to match the shear stress across the plastic zone, and provide the value of $\mathrm{B}=0.06 \mathrm{pa}^{3}$, where $\mathrm{p}$ is the internal pressure in the plastic zone (analogous to the hardness), supporting the load $\mathrm{P}$, such that $\mathrm{P}=\pi \mathrm{a}^{2} \mathrm{p}$, where $a$ is the contact radius.

The initiation of a median cracks is taken to be controlled by the $\sigma_{\theta \theta}$ component of the stress field at $\theta=0$, and $\mathrm{r}=\mathrm{a}$, and that of radial cracks by the $\sigma_{\phi \phi}$ component of the stress field at $\theta=\pi / 2, \mathrm{r}=\mathrm{a} .[25,26]$ Therefore, we have at peak load, 
$\left.\sigma_{\theta \theta}\right|_{\theta=0}=0.065 p>0$ and

$\left.\sigma_{\phi \phi}\right|_{\theta=\pi / 2}=-0.13 p<0$

Consequently, during loading on an unstressed surface median cracking is possible, while radial cracking is extremely unlikely. In-situ observations [27] of cracking confirm this for the glass being used. At complete unload, $\mathrm{P}=0$, and we obtain

$\left.\sigma_{\theta \theta}\right|_{\theta=0} \approx-0.06 p<0$ and

$\left.\sigma_{\phi \phi}\right|_{\theta=\pi / 2} \approx 0.12 p>0$

i.e., at complete unload there is a strong driving force for radial crack initiation, approximately twice that for median cracking at peak load.

Now the equi-biaxial stress state due to the ion-exchange process can be represented in Cartesian coordinates as:

$\sigma_{x}=\sigma_{y}=\sigma(z) ;$ All other components $=0$

which in the spherical coordinates of the problem can be expressed as

$$
\sigma_{r r}=\sigma(z) \sin ^{2} \theta
$$

$\sigma_{\theta \theta}=\sigma(z) \cos ^{2} \theta$

$\sigma_{\phi \phi}=\sigma(z)$

$\sigma_{r \theta}=\sigma(z) \sin \theta \cos \theta$

Therefore the residual stress contributions along the loading axis $(\theta=0), \sigma_{\theta \theta}=\sigma(z)$ is pertinent to median crack initiation, and at the surface $(\theta=\pi / 2), \sigma_{\phi \phi}=\sigma(\mathrm{z})$ are pertinent to radial crack initiation.

\section{DISCUSSION}

\subsection{Crack Initiation Observations:}


Considering the strength results (Fig. 4), and arguments concerning the stress distribution and relaxation with increasing exchange time (Section 3), the functional form of $\sigma(\mathrm{z})$ is likely to be maximum at $\mathrm{z}=0$ for the $3 \mathrm{hr}$. exchange samples. Stress relaxation occurs most rapidly in the near-surface layers of the material, because the rate of stress relaxation is roughly proportional to the stress [23]. However, with increasing exchange time, the extent of ion-penetration also increases. The net effect of these two events is that the surface compressive stress maximum moves inwards from the surface. These two cases are schematically depicted in Fig. $6 \mathrm{a}$ and b, by the shaded band, and in Fig. 7a, b by the dotted lines: in (a) the maximum is at the surface, and stress decays in the z-coordinate, whereas in (b), the stress maximum is below the surface. Referring again to Fig. 4, it is clear that stress-relaxation plays a significant role in determining the strength of the material: longer exchange times lead to reduced strengthening, consistent with the residual stress depictions in Fig. 6 and 7.

The observations of cracking during loading, and during and after unloading with a Vickers indenter (Fig. 1a, b) can be summarized as follows: (1) the average load to cause cracking during loading is approximately identical, except for $3 \mathrm{hr}$. exchange samples, and there is a large scatter in these loads, (2) The loads required to cause fragmentation for shorter exchange times, during or after the unload cycle (Fig. 1b) are higher for the shortest exchange time and, (3) Catastrophic cracking loads during the continued loading cycle are $\sim 2-3$ times larger than the load needed during/after unloading.

Now let us consider observation (1): Fractographic observations (Fig. 2) reveal that median crack initiation begins the fragmentation process. During the loading cycle, median cracks can initiate from the base of the plastic zone (Eq. 2). Although the stress driving the incipient median cracks remains constant during the loading cycle, the hardness impression size, and presumably, the size of the nuclei for these cracks increase as a function of load [20, 24]. For instance for soda-lime glass, the threshold load for median cracking is $50 \mathrm{~N}$, and the probability of median cracking rises to $75 \%$ for a $100 \mathrm{~N}$ peak load [27].

The plastic zone underneath the indenter is taken to be hemi-spherical, with radius=a, the indentation size in keeping with assumptions in Ref. 25 , and 26. For Vickers geometry, this radius is $\sim 3.5$ times the actual penetration of the diamond tip into the material. Using the measured hardness, $\mathrm{H}$, of the base glass of $6.4 \mathrm{GPa}$, and 
noting that the intrinsic hardness of the ion-exchanged surfaces are the same as the base glass, the values of this radius for the average loads at failure during loading (Fig. 1a), are tabulated in Table 1. These values range from $\sim 180 \mathrm{~m}$ to $\sim 250 \mathrm{~m}$, all greater than the depth of ion-penetration save the $96 \mathrm{hr}$. exchange treatments. Therefore, it appears that the plastic zone must penetrate through to the zone of tension to cause failure, thereby leading to higher initiation loads. However, the fact that the $3 \mathrm{hr}$. exchange samples have the highest load (and highest average loads) indicates that there are additional effects. The action of the compressive surface stress on the hardness impression, and on the plastic zone, to prevent ingress of moisture to the incipient crack tips, analogous to moisture-effects in the initiation of radial cracks might be important as well [24]. For the $3 \mathrm{hr}$. exchange, the surface compressive stress $\sigma(\mathrm{z})$, at $\mathrm{z}=0$ is the highest value, and probably the most effective in constraining access to moisture. With increasing exchange time, the compressive $\sigma(z$, at $\mathrm{z}=0$, surface $)$ values drop, and the compensating $\sigma_{\mathrm{T}}$ values increase at the median crack initiation site. Hence there is a slight decrease in the average load to crack initiation. By equating the contact pressure, p, to the hardness, H, Eq. 2 can be used to estimate the stress required for median crack initiation to be about $420 \mathrm{MPa}$. Therefore, the small values of compensating tension, up to $60 \mathrm{MPa}$, have only a minor influence on reducing the load to cracking. For the $96 \mathrm{hr}$. exchange, the zone of compression extends deep enough to interact with the crack initiation sites, and the load to initiation is pushed slightly higher.

Next let us turn to observation (2) and (3), that the load required to cause cracking during/after unload is highest for the shortest exchange times (Fig. 1b), and that this load is much lower than the load to cause cracking during loading (Fig. 1a,b). Eq. 6 reveals that there is a high driving force for radial crack initiation, $\sigma_{\phi \phi}$ at complete unload on the surface. In fact, this stress increases during unloading, as the compressive stress due to the point force (P) gradually reduces to zero at the surface [26]. Eq. 8 indicates that the super-imposed stress due to the ionexchange is $\sigma(\mathrm{z})$. For the shortest exchange times, $\sigma(\mathrm{z})$ at the surface is the highest, due to minimal stress relaxation (Fig. 6). Hence the loads required to pop-in a radial crack are the highest for the shortest exchange times. As the patterns of fragmentation obtained are not different from those shown in Fig. 3, we conclude that the radial cracks propagate downwards, form a radial-median crack system, and cause the disintegration of the samples. Comparison of Eq. 3 with Eq. 6 indicates that the driving force for radial initiation is approximately twice that for median cracks. It is also likely that due to reduced constraint and easy access to moisture, the crack nuclei for radial cracking might be more easily activated. These factors lead to the reduced load needed for radial pop-in at lower loads. 


\subsection{Fragmentation Observations:}

The change in fragmentation mode between the indentation-initiated samples (Fig. 3) and the biaxialinitiated fracture (Fig. 5) is noteworthy. Parallelepiped shaped fragments, with number of sides, $\mathrm{n} \geq 4$ are common in the former case, while in the latter, triangular wedge shaped elements are seen. For indentation-initiated fractures, the loading is quasi-static and the strain-energy dominant solution by Glenn et al $[28,29]$ as further developed for a ion-exchanged system in Tandon and Glass [30] may be used. The solution indicates that the average fragment size is inversely proportional to the square of the internal tension. ${ }^{\S}$ Although attempts to verify the exact form of the relationship were not made, it is apparent that the average fragment size decreases with increasing time of exchange. It was also observed using birefringence that the fragments retain a portion of the original strain energy. This violates the assumption in the analysis that all strain energy is used to create fragments: hence fragment sizes measured will be larger than predicted by the energy-balance approach. It is our opinion that actual fragment sizes will be larger than those predicted by approaches that equate total strain energy to fracture energy, because dissipative mechanisms such as local heating, and acoustic energy are often ignored. Calculations for the total strain energy, taking into account the measured values of tension, and approximated values of compression, and their relative depths, reveal another important feature of the energy partitioning: even though the strain energy due to the compressive stress is between 1.5-10 times more than that from the tension, fragmentation in the indentationinitiated fracture appears to be dominated by the tensile strain $[11,31]$.

Another observation from Fig. 3 is that the largest size fragments are near the origin, with the size decreasing as the cracking proceeds towards the circumference. It is tempting to attribute this to a reduction of the branching distance for the second and third generation of cracks. For tempered glass, Aratani et al. [14] noted an increase in fragment size density (FSD), i.e., a decrease in fragment size at a particular distance away from the crack initiation site. Increasing the sample size moved this point further from the point of crack initiation. They attributed this increase in fragment density to the interaction of the reflected stress wave with the crack fronts. On the other hand, Nakasa and Nakatsuka [32] used a free energy minimization approach to show that for crack propagation and branching under axi-symmetric tension, if it can be assumed that the cracking does not alter the prior stress state, the

\footnotetext{
${ }^{\S}$ Here the internal tension plays the same role as the critical stress, $\sigma^{*}$ in Eq. 6 in Ref. 29 , and Eq. 20 in Ref. 30
} 
stable crack length for the $(i+1)^{\text {th }}$ branch is larger than that for the $i^{\text {th }}$ branch. They did not consider any effect of stress wave reflections on crack patterns. Analysis of observations in Glass et al. [33] for this ion-exchanged glass system has not been able to confirm this prediction; however within the scatter of data, the branching lengths are not different. The observed discontinuity in FSD in our case cannot be attributed solely to a reflected stress-wave interaction with the crack front as found by Aratani et al. [14] for tempered glass, because in our case the discontinuity moves closer to the origin with increasing tension. If stress-wave effects on FSD were significant, the position of the discontinuity would remain more or less constant, at least in the range of tension values where up to 3-4 branching events are evident in our samples (Fig. 3a-d). We conducted a simple geometric simulation of cracking with the following rules: (1) the branch size is a constant, (2) at this branching size a predetermined number of branches are formed, and (3) that a crack stops when it intersects another crack. It was found that this simple geometrical construction is able to reproduce the observed reduction of fragment size with distance from crack initiation. Therefore, it appears that the central tension (which determines the branching length), and the number of branches may be adequate to describe the FSD from point impacts, and simulations for practically important cases may only need to capture geometrical branching effects.

The strain rate for the biaxial-stressed samples is $\sim 10^{-3} \mathrm{~s}^{-1}$, placing this loading in the quasi-static regime. The fragmentation pattern is similar to that for unexchanged disks in flexure, and to that for other ceramic disks fractured in flexure [34-35], but with more fragmentation. As the loading is quasi-static, the resultant stress state during fracture can be described by the prior stresses. These can be inferred from the stress relaxation behavior of the glass, and from the strength, and are depicted by the solid lines in Fig. 7 (a, b) for short (say $<48$ hrs), and long ( $>48 \mathrm{hrs}$ ) exchange times for the centrally loaded portion of the disk. For short times, the strength is very high because the small flaws in the body ( 8-10 micron in size) are in the range of the maximum compressive stress, whereas it is lower for longer times due to stress relaxation. Now, assuming that the compressive stress is uniform over the flaw, an approximation ${ }^{\dagger}$ for the resultant stress (full line in Fig. $7 \mathrm{a}, \mathrm{b}$ ) near the surface, is that it is $\sim$ equal to the strength of the un-exchanged material. Therefore, when a flaw initiates, and propagates a small distance it is driven by stress which is approximately equal to the strength of un-exchanged material. However, as the flaw grows, it begins to experience the large resultant stress below the surface (Fig. 7a). This high circumferential stress leads to

\footnotetext{
${ }^{\dagger}$ A precise calculation would involve the shape of the stress profile, shape of the flaws, effects of crack closure, and any changes to the flaw due to the ion-exchange process itself, and is too complicated due to the large number of unknowns.
} 
the formation of a large number of branches. These branches propagate to the edge of the sample with little or no further branches being formed, because the bending stress drops off outside the central loaded area. This creates wedge shaped fragments. The biaxial loading induced radial stress causes cracks perpendicular to these main cracks (see marking in Fig. 5d, e). We hypothesize that the fracture process in the highly stressed outer skin is nearly complete before the cracks proceed through the original zone of tension because not much additional fragmentation of the type observed in Fig. 3 (from residual tension) is seen. As these large cracks are driven through the thickness of the sample, the stresses ahead may be sufficiently relaxed, so as to preclude fragmentation due to residual tension. For long exchange times, the resultant stress for initiation is similar; however, as the crack grows, the stresses actually drop-off with depth. Hence few branches and very few cracks perpendicular to the main crack are seen (see for instance, Fig. $5 \mathrm{f}$ which shows a $144 \mathrm{hr}$. exchange sample where perpendicular cracks are absent).

For this ion-exchanged system, it has been shown that fragmentation behavior is not simply a material response.Fragment shape and size distributions are significantly influenced by the local stress distributions. It is also demonstrated that fragmentation can be induced at low loads, if a sharp penetrator is loaded, and then unloaded. The mode of loading and the ion-exchange conditions for attaining a fragment size can be used as inputs in designs for applications where a particular fragment size is of interest. For armor and display applications, failure under bending loads, which may produce shard-like fragments that could be injurious, can be expected. In the former application, dynamic loading could induce time varying stress states at the same location. Also, as Brazier et. al [36] have shown, impact on glass with a soft bullet leads to bending stresses far from the impact site on the impacting side, whereas for a hard bullet the stresses are more localized. It is also expected that the initial penetration of a projectile may lead to cracking similar to the one under an indentation, while the bending of the structure may lead to tension on the far side. Hence the material response under both the loading conditions studied here will be useful for establishing the system fragmentation response.

\section{CONCLUSIONS}

- $\quad$ The superposition of the residual stress field and the indentation stress field provides a qualitative understanding of crack initiation on stressed surfaces. The analysis shows that the driving force for radial 
cracking is approximately twice that for median cracking, and a lower load to initiate fragmentation in the load-unload experiment is expected and observed.

- Fragmentation by sharp indentation appears to couple with the tensile zone in the exchanged glass despite the fact that the strain energy from the compressive region is high. In bending, fragmentation behavior is dominated by the resultant of the applied tensile stress and residual compressive stress.

- Fragmentation in the same material produces different fragment shapes, and size distributions depending on the loading stress distribution.

- In practical loading situations, different parts of a large body are usually exposed to different stress states. Simulation of such behavior should not only be informed by the stress distributions in the material, but also by the material response observed here under different stress states.

\section{ACKNOWLEDGEMENTS}

Sandia National Laboratories is a multi-program laboratory managed and operated by Sandia Corporation, a wholly owned subsidiary of Lockheed Martin Corporation, for the U.S. Department of Energy's National Nuclear Security Administration under contract DE-AC04-94AL85000.

\section{REFERENCES}

1. Grady DE. Length scales and size distributions in dynamic fragmentation. Int J Fract 2010; 163:85-99.

2. Kirchner HP. Strengthening of Ceramics: Treatments, Tests, and Design Applications. New York: MarcelDekker; 1979.

3. Gardon R. Thermal Tempering of Glass, Glass: Science and Technology V. New York: Academic Press; 1980

4. Kistler S. Stresses in Glass Produced by Nonuniform Exchange of Monovalent Ions. J Am Ceram Soc 1962; 45 : 59-68.

5. Virkar AV, Huang JL, Cutler RA. Strengthening of Oxide Ceramics by Transformation-Induced Stresses. J Am Ceram Soc 1987; 70:164-170.

6. Sglavo VM, Bertoldi M. Design and Production of Ceramic Laminates with High Mechanical Resistance and Reliability. Acta Materialia 2006; 54: 4929-37. 
7. Guicciardia S, Nagliatia M, Melandria C, Pezzottib G, and Scitia D, Effects of Residual Stresses on the Fracture Properties of Non-oxide Laminated Composites. J Eur Cer Soc 2007; 27: 351-6.

8. Barsom JM. Fracture of Tempered Glass. J Am Ceram. Soc 1968; 51: 75-8.

9. Gulati ST. Frangibility of the Tempered Soda-Lime Glass Sheet. Proc. of Glass Proc. Days, $72-76$ Finland

Tampere. 1997.

10. Warren PD. Fragmentation of Thermally Strengthened Glass, in Fractography of Glasses and Ceramics IV, Eds. Varner JR, Quinn GD 2001; 389-400, American Ceramic Society, Ohio

11. Tandon R. Unpublished Results.

12. Acloque P, Morain M. Processus Differes dans la fragmentation du verre Trempe (in French). Verres et Refr. $1966 ; 20: 171-81$.

13. K. Akeyoshi and E. Kanai, "Mechanical Properties of Tempered Glass," Rep. Res. Lab. Asahi Glass, 17 (1) 23$36,(1967)$

14. Aratani S, Oginoh K, Takatsu KM. Crack Propagation in Tempered Glass. J Soc Mat Sc Japan 1991; 40: 46-50

15. Takahashi K. Fast Fracture in Tempered Glass. Key Eng Mat 1999; 66: 9-18.

16. Nielsen JH, Olesen JF, Stang H. The Fracture Process of Tempered Soda-Lime-Silica Glass. Exp Mech 2009; 49: 855-70.

17. Zijlastra AL, Burggraaf AJ. Strength and Fracture Behavior of Chemically Strengthened Glass in Connection With the Stress Profile, Part II. J Non-Crys Sol 1969; 1:163-85.

18. Hill MJC, Donald IW. Stress profile Characteristics and Mechanical Behavior of Chemically Strengthened Lithium Magnesium Alumino-silicate Glasses. Glass Tech 1989; 30: 123-7.

19. Bouyne E, Gaume O. Fragmentation of Thin Chemically Tempered Glass Plates, Proc. Int. Congr. Glass Volume 2, Extended Abstracts, Scotland, (2001)

20. Morris DJ, Myers SB, Cook RF. Indentation Crack Initiation in Ion-Exchanged Glass. J Mat Sci 2004; 39: 23992410.

21. Abrams M, Shen J, Green DJ. Residual Stress Measurement in Ion-Exchanged Glass by Iterated Birefringence and Etching. J Test Eval 2004; 32: 1-7. 22. Tandon R and Green DJ. Residual Stress Determination Using Strain Gage Measurements. J Am Cer Soc 1990; 73: 2628-33. 
23. Sane AY, Cooper AR. Stress Buildup And Relaxation During Ion-Exchange Strengthening of Glass. J Am Ceram Soc 1987; 70: 86-9.

24. Lawn BR, Dabbs TP, Fairbanks CJ. Kinetics of Shear-Activated Indentation Crack Initiation in Soda-Lime Glass. J Mat Sci 1983; 18: 2785-97.

25. Yoffe EH. Elastic Stress Fields Caused by Indenting Brittle Materials. Phil Mag A 1982; 46: 617-28.

26. Cook RF, Pharr GM. Direct observation and analysis of indentation cracking in glasses and ceramics. J Am Cer Soc 1990; 73: 787-817.

27. Tandon R, Green DJ, Cook RF. Surface Stress Effects on Indentation Fracture Sequences. J Am Cer Soc 1990; 73: $2619-27$.

28. Glenn LA, Chudnovsky A. Strain-Effects on Dynamic Fragmentation. J Appl Phys 1986; 59: $1379-80$.

29. Glenn LA, Gommerstadt BY, Chudnovsky A. A Fracture Mechanics Model of Fragmentation. J Appl Phys 1986; 60: 1224-26.

30. Tandon R, Glass SJ, Controlling the Fragmentation Behavior of Stressed Glass in Fracture Mechanics of Ceramics, Eds.: R.C. Bradt, D. Munz, M. Sakai, K.W. White, 2005:14: 77-92.

31. Kooi JE, Tandon R, Glass SJ, Mecholsky JJ. Analysis of Macroscopic Crack Branching Patterns in Chemically Strengthened Glass. J Mat Res 2008; 23: 214-25.

32. Nakasa K, Nakatsuka JI. Crack Initiation, Propagation, and Branching in a Disk of Brittle Material Under Axisymmetric Tension. Eng Fract Mech 1991; 39: 661-70.

33. Glass SJ, Tandon R, Heller D. Characterization of Crack Branching and Fragmentation Patterns for IonExchanged Glass. Fractography of Glasses and Ceramics V, 2007; 199: 407-20.

34. Shetty DK, Rosenfield AR, Duckworth WH. Crack Branching in Ceramic Disks Subjected to Biaxial Flexure. J Am Ceram Soc 1983; 66: C10-C12.

35. Quinn GW, Quinn JB, Mecholsky JJ, Quinn GD. Modeling of Crack Propagation Using Fractal Geometry., Cer Eng Sci Proc 2005; 26: 77-84.

36. Brajer X, Forquin P, Gy R, Hild F.The Role of Surface and Volume Defects in the Fracture of Glass under Quasi-Static and Dynamic Loading. J Non-Cryst Sol 2003; 316: 42-53. 
List of Tables:

Table 1. Details of exchange times, central tension, ion-penetration depths, and calculated plastic zone radii for various exchange temperatures 


\section{List of Figures:}

Fig 1a. Loads causing cracking and fragmentation when failure occurs during loading for various exchange times. The individual data points and average values (filled circles) for each exchange time are shown.

Fig $1 \mathrm{~b}$ Time until fragmentation occurred after unloading as a function of maximum load. The data points at time $=0$ indicate that cracking occurred during unloading.

Fig. 2 Montage of images showing the fracture surface for a $24 \mathrm{hr}$., $450^{\circ} \mathrm{C}$ sample loaded monotonically to fracture. Bottom left is the fracture origin. The crack pops-in, propagates through the thickness, and then sweeps through the sample, from left to right. The black dashed line marks the beginning of the first hackle.

Fig. 3: Fragmentation patterns for $1.8 \mathrm{~mm}$ thickness disks, exchanged for different times at different temperatures. All disk diameters are $25.4 \mathrm{~mm}$, and full disk images are shown. (a) $3 \mathrm{hrs}$., $500^{\circ} \mathrm{C}$, Tension= $37 \mathrm{MPa}$, (b) $6 \mathrm{hrs}$, $500^{\circ} \mathrm{C}, 45 \mathrm{MPa}$ (c) $12 \mathrm{hrs} ., 500^{\circ} \mathrm{C}, 55 \mathrm{MPa}$, (d) 24 hrs., $500^{\circ} \mathrm{C} .75 \mathrm{MPa}$, (e) 48 hrs., $500^{\circ} \mathrm{C}, 107 \mathrm{MPa}$, (f) $96 \mathrm{hrs}$., $500^{\circ} \mathrm{C}, 140 \mathrm{MPa}$, and (g) $12 \mathrm{hrs} .450^{\circ} \mathrm{C}, 37 \mathrm{MPa}$. Indentation loads varied, and fracture occurred during or after unloading.

Fig. 4 Strength of samples of two thicknesses for two exchange temperatures. the strength decreases with increasing exchange time due to surface stress relaxation. The boxed region is the range of strength for base glass samples.

Fig 5 The top-views of $1.8 \mathrm{~mm}$ thick samples exchanged at $500^{\circ} \mathrm{C}$, and fractured in biaxial flexure, for several exchange times are shown in Fig. 5a-g. (a) 3 hr. ex., Strength=681 MPa, (b) 24 hr. ex., Strength=588 MPa, (c) 96 hr. ex., Strength=446 MPa, (d) Magnified view of the $3 \mathrm{hr}$. exchange sample. Crack origin at (a), first branching at (b). (c) marks some of the regions where "tertiary" cracks are seen, (e) Magnified view of the $96 \mathrm{hr}$. exchange sample. Crack origin at (a), first branching at (b). (c) marks some of the regions where "tertiary" cracks are seen, and (f) Magnified view of $144 \mathrm{hr}$. exchange sample. The initial crack has a large number of branches, and the incidence of "tertiary" cracking is minimal.

Fig.6a. Schematic showing the spherical co-ordinate system centered at the initial point of contact of the conical indenter with the sample surface. The triangular region is the hardness impression, and the plastic zone has the radius a. All cracking is assumed to initiate at the edges of this zone, either on the surface (radial) or in the bulk (median). The shaded region is the zone of compression for short exchange times, with maximum stress at the surface. The compensating tension is below this region.

Fig. 6b. Schematic of a compression profile after significant relaxation has occurred: the compressive maximum has moved to a sub-surface location under the surface (darker portion of the shaded region).

Fig.7a. Schematic showing the quasi-static stress distribution in a short exchange time sample: the dotted line is the residual stress profile imparted by the ion-exchange with maximum compression at the surface, the dashed line is bending load distribution, and the solid line is the resultant.

Fig.7b. Quasi-static stress distribution in a long exchange time sample, with same notations as in (a). Note that the bending load is lower in this case and the resultant stress could drop close to zero below the surface due to shift in the maxima in the residual profile. 
Table 1. Details of exchange times, central tension, ion-penetration depths, and calculated plastic zone radii for various exchange temperatures

\begin{tabular}{|c|l|c|c|c|c|}
\hline $\begin{array}{l}\text { Exchange } \\
\text { time (hr.) }\end{array}$ & $\begin{array}{l}\text { Central tension, } \\
\sigma_{\mathrm{T}}(\mathrm{MPa}), \\
500^{\circ} \mathrm{C} \text { treatment }\end{array}$ & $\begin{array}{l}\sigma_{\mathrm{T}}(\mathrm{MPa}), \\
450^{\circ} \mathrm{C} \text { treatment }\end{array}$ & $\begin{array}{l}\text { Penetration } \\
\text { Depth, } \\
\delta_{500}(\mathrm{~m})\end{array}$ & $\begin{array}{l}\delta_{450} \\
(\mathrm{~m})\end{array}$ & $\begin{array}{l}\text { Plastic zone radius at avg. } \\
\text { load to cause fracture } \\
\text { during loading }(\mathrm{m})\end{array}$ \\
\hline 3 & 37 & 16 & 64 & 35 & 252 \\
\hline 6 & 45 & 23 & 90 & 49 & 203 \\
\hline 12 & 55 & 37 & 128 & 69 & 200 \\
\hline 24 & 75 & 47 & 180 & 98 & 206 \\
\hline 48 & 107 & 60 & 255 & 139 & 186 \\
\hline 96 & 140 & 87 & 360 & 196 & 206 \\
\hline
\end{tabular}




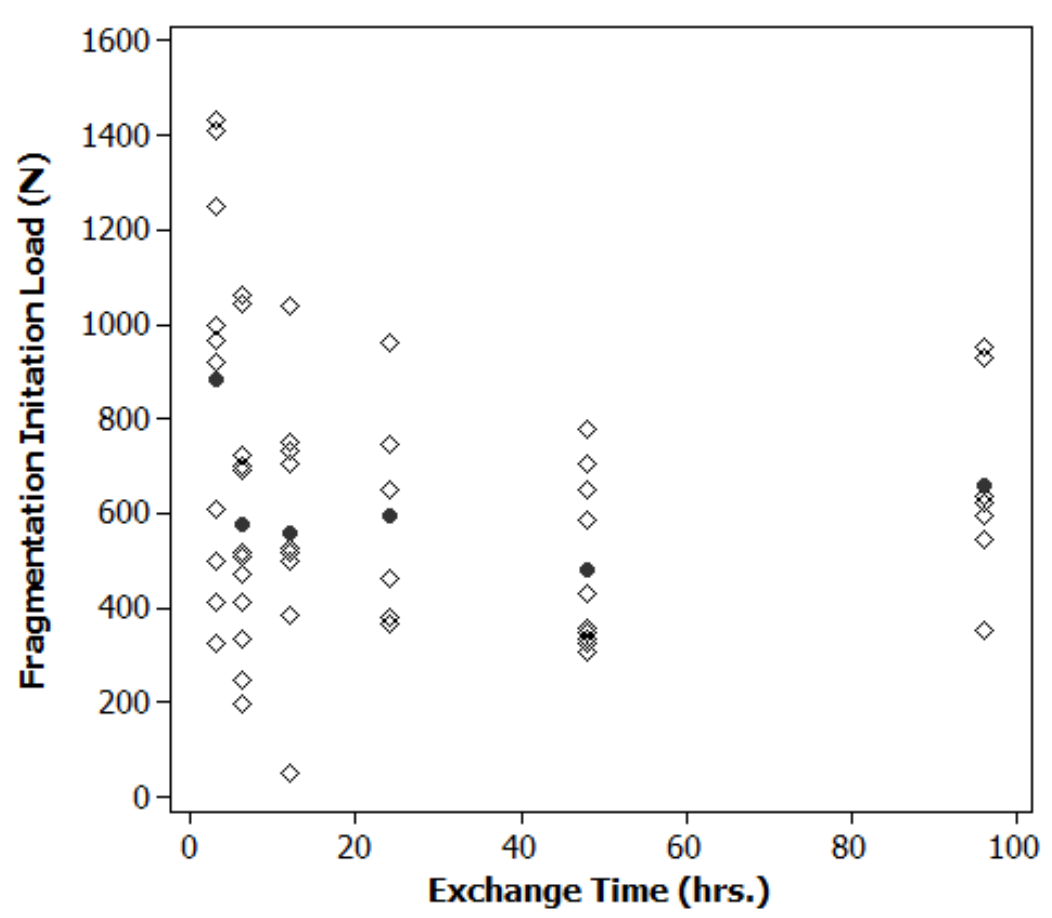

Fig 1a. Loads causing cracking and fragmentation when failure occurs during loading for various exchange times. The individual data points and average values (filled circles) for each exchange time are shown.

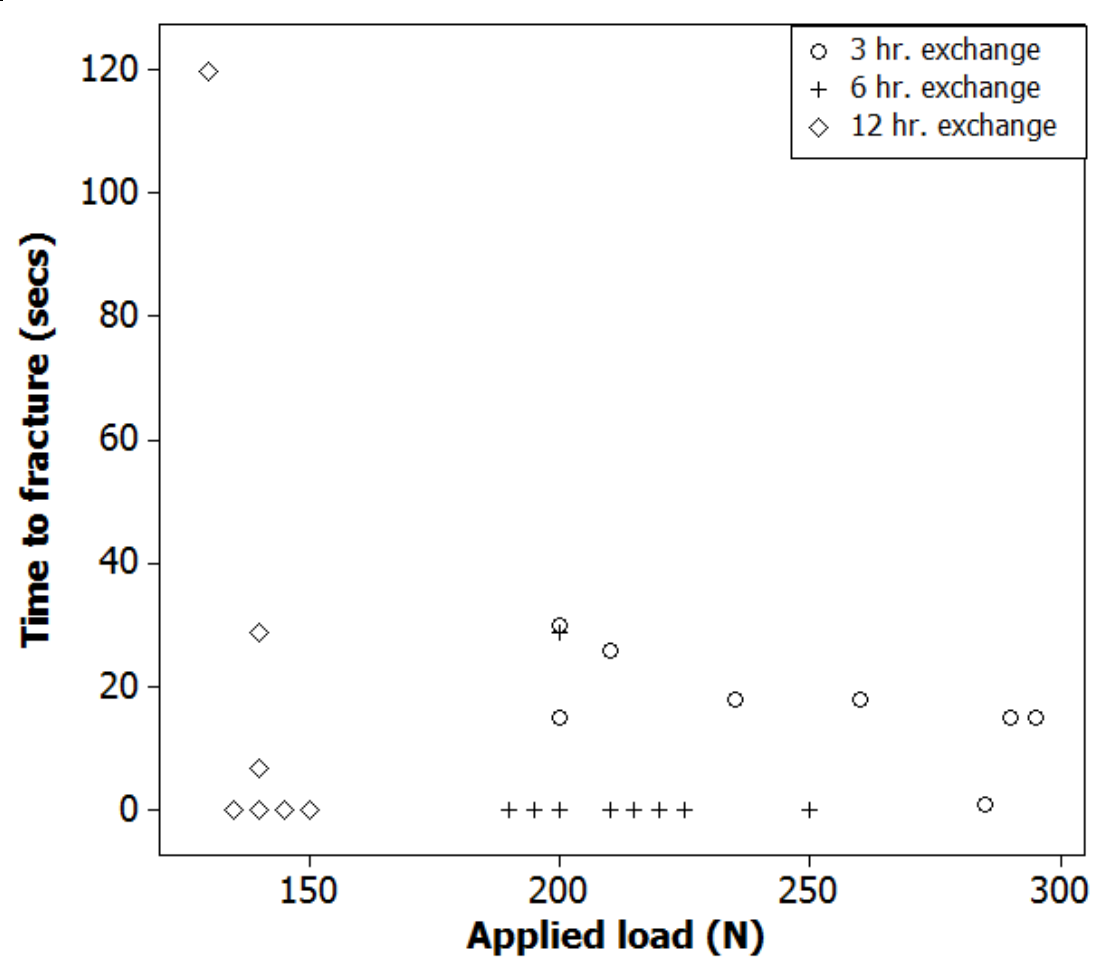

1b. Time until fragmentation occurred after unloading as a function of maximum load. The data points at time $=0$ indicate that cracking occurred during unloading. 
Figure 2

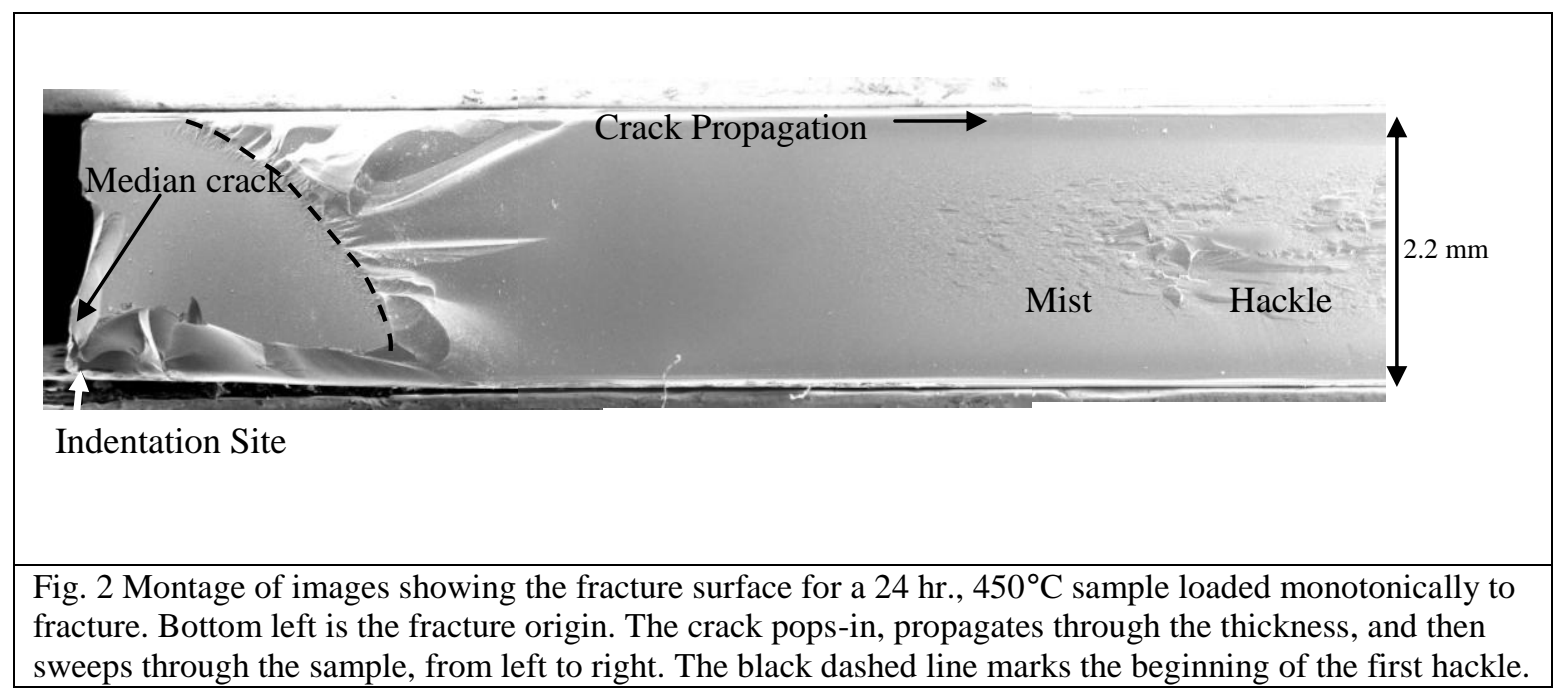




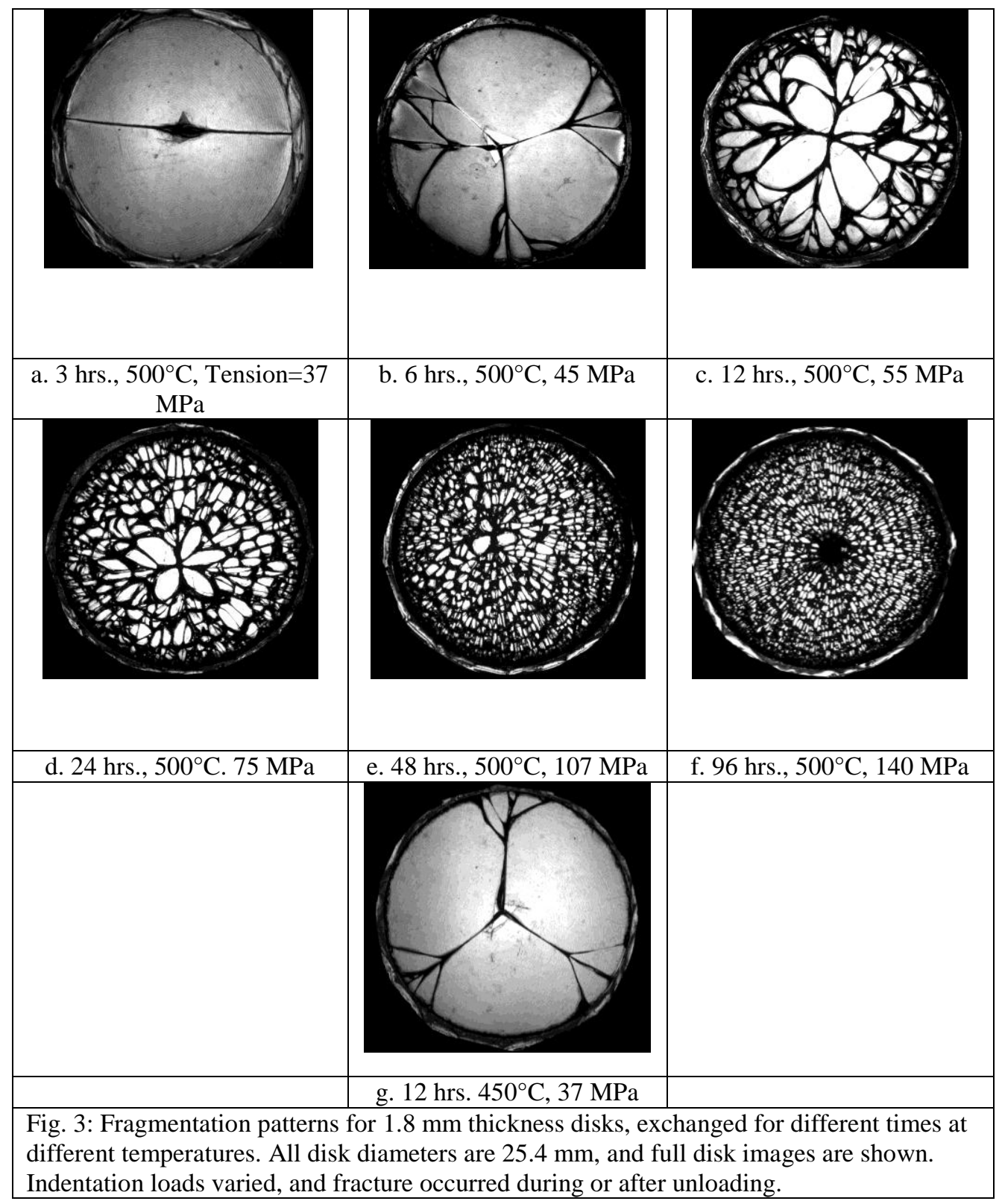




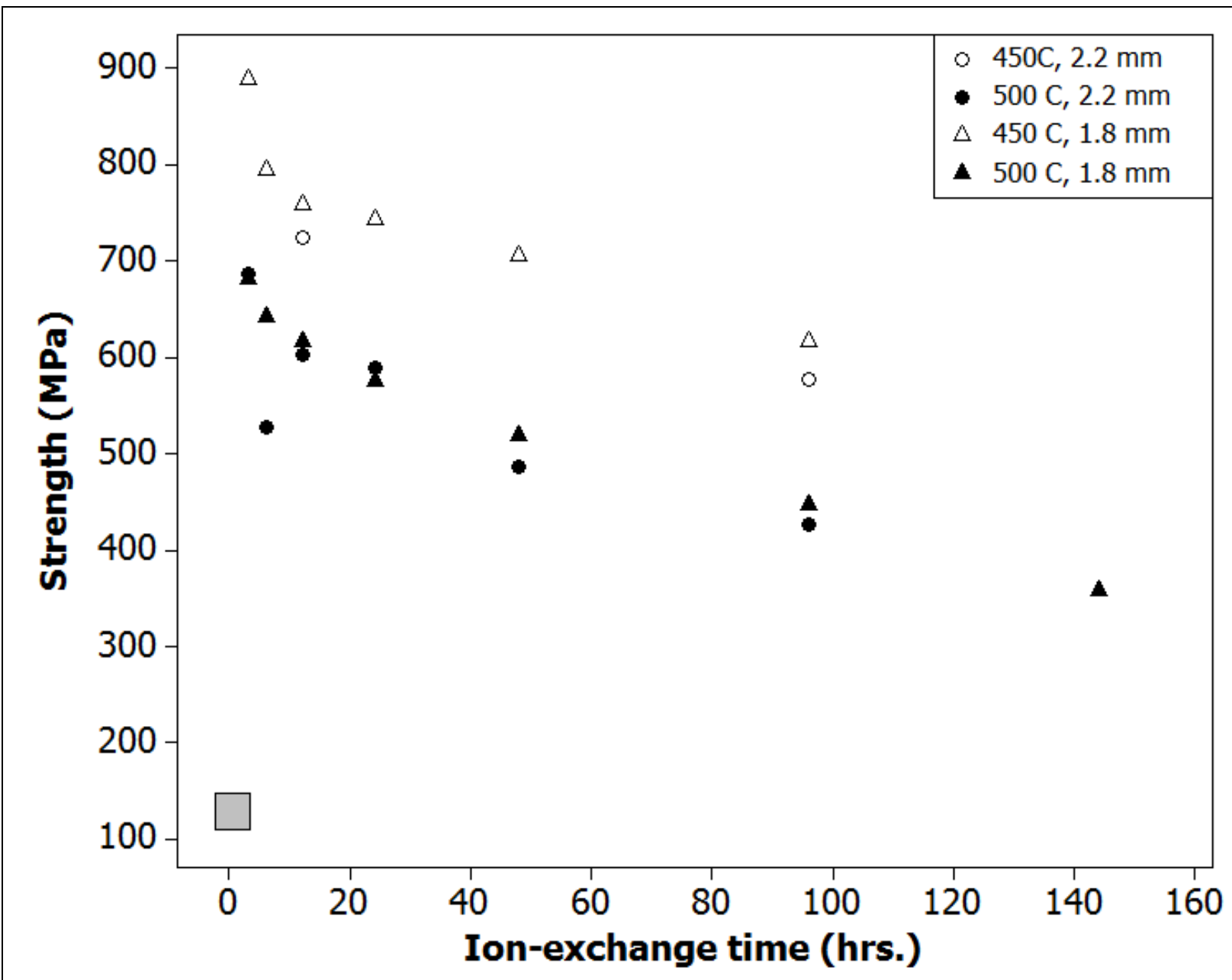

Fig. 4 Strength of samples of two thicknesses for two exchange temperatures. Strength decreases with increasing exchange time due to surface stress relaxation. The boxed region is the range of strength for base glass samples. 

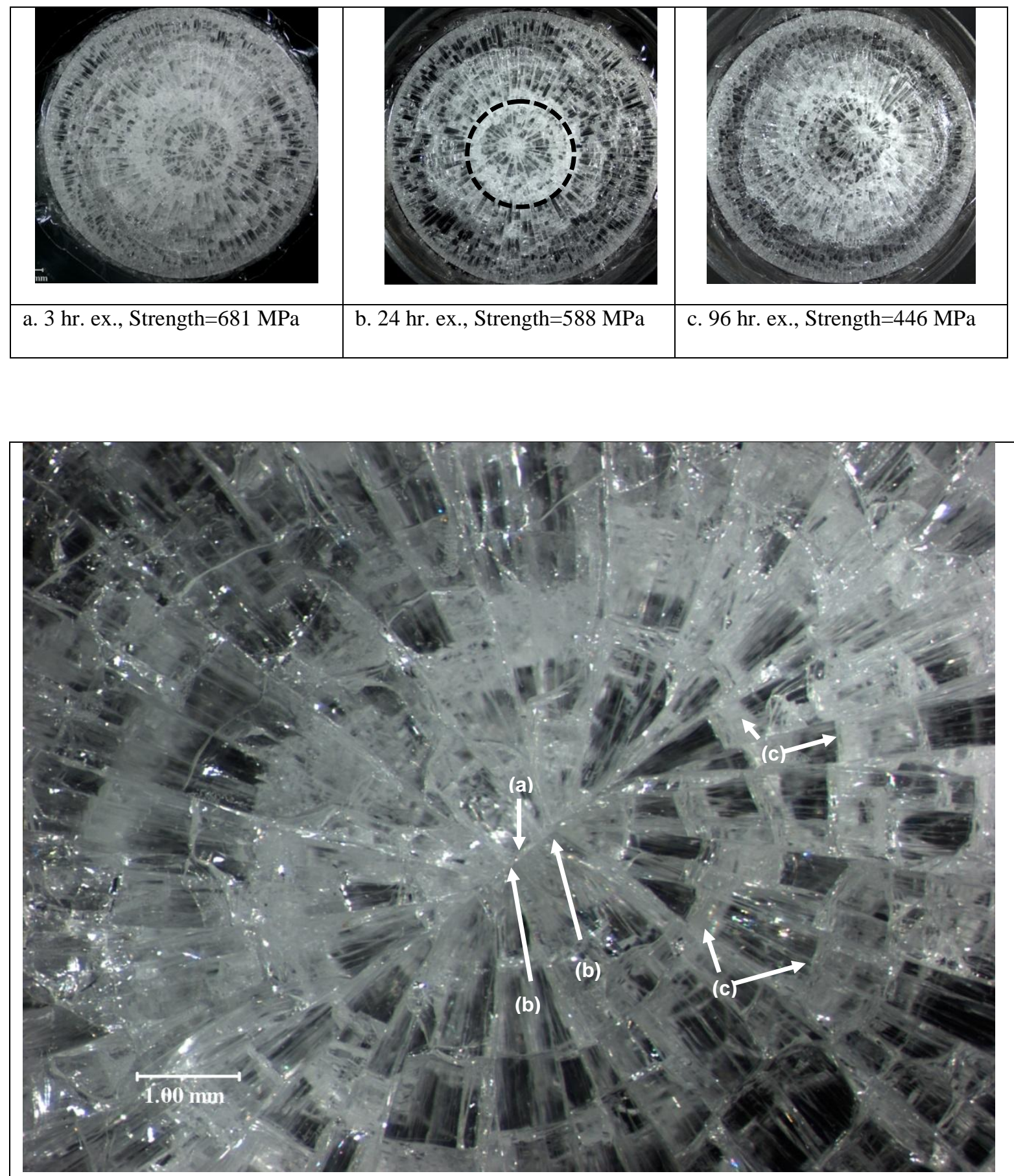

d. Magnified view of the $3 \mathrm{hr}$. exchange sample. Crack origin at (a), first branching at (b). (c) marks some of the regions where "secondary" cracks are seen. 


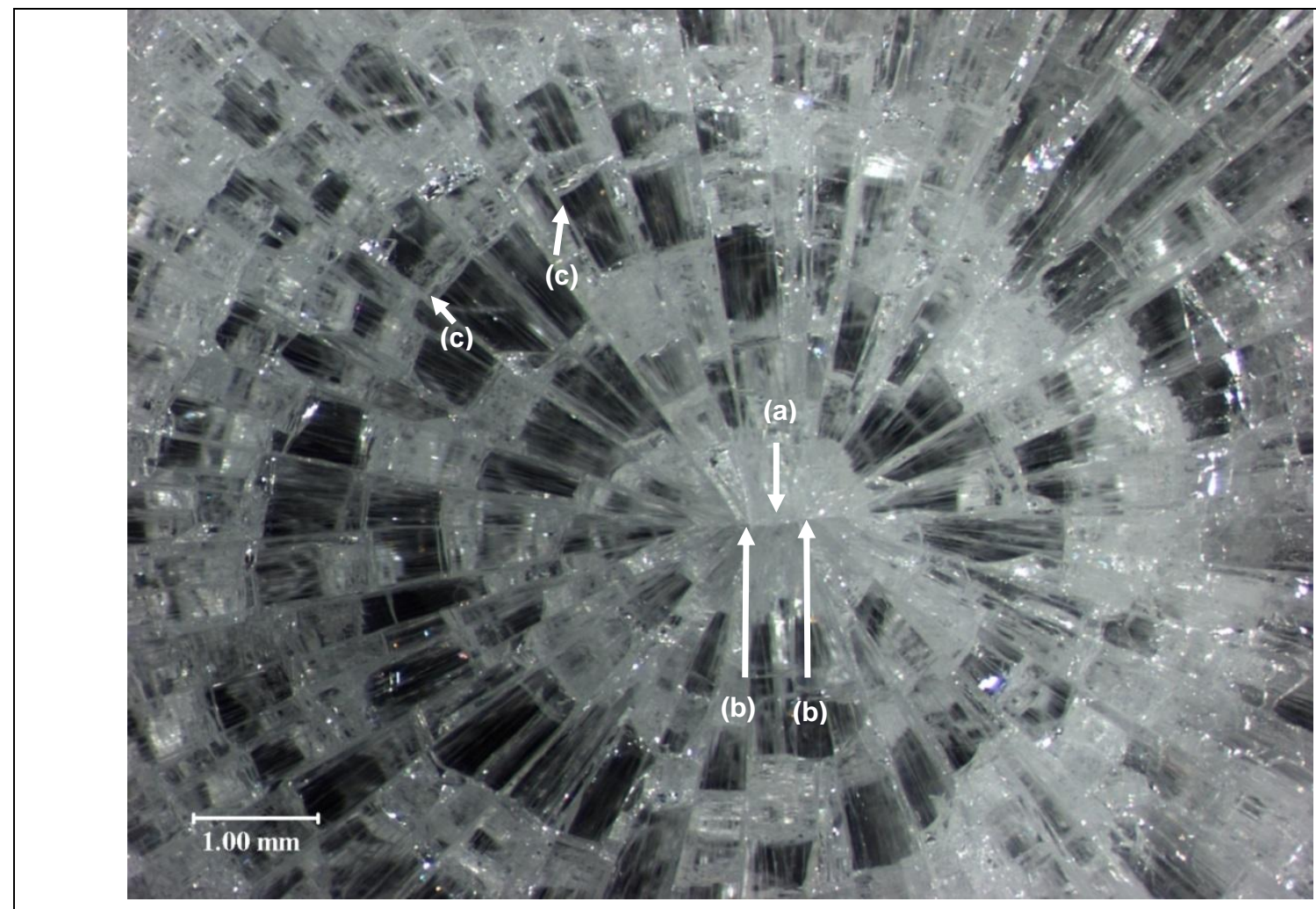

e. Magnified view of the $96 \mathrm{hr}$. exchange sample. Crack origin at (a), first branching at (b). (c) marks some of the regions where "secondary" cracks are seen.

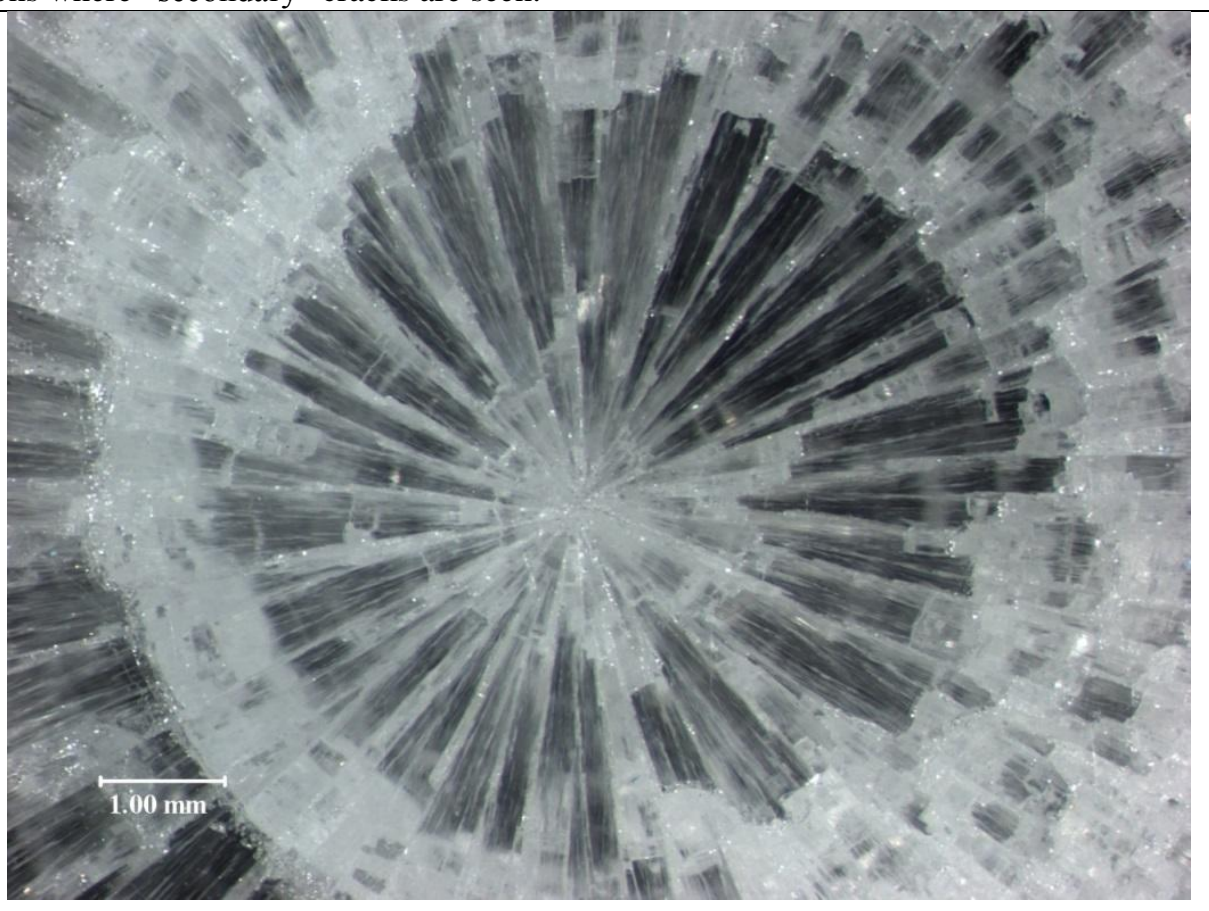

f. Magnified view of $144 \mathrm{hr}$. exchange sample. The initial crack has a large number of branches, and the incidence of "secondary" cracking is minimal.

Fig 5. The top-views of $1.8 \mathrm{~mm}$ thick samples exchanged at $500^{\circ} \mathrm{C}$, and fractured in biaxial flexure, for several exchange times. 


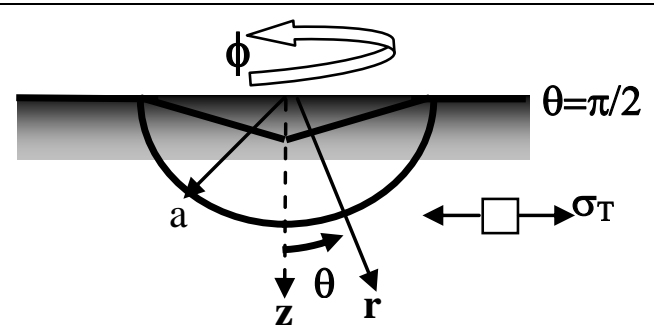

Fig.6a. Schematic showing the spherical co-ordinate system centered at the initial point of contact of the conical indenter with the sample surface. The triangular region is the hardness impression, and the plastic zone has the radius a. All cracking is assumed to initiate at the edges of this zone, either on the surface (radial) or in the bulk (median). The shaded region is the zone of compression for short exchange times, with maximum stress at the surface. The compensating tension is below this region.

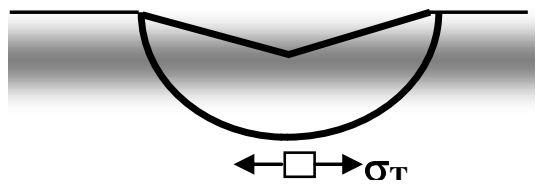

Fig. 6b Schematic of a compression profile after significant relaxation has occurred: the compressive maximum has moved to a sub-surface location under the surface (darker portion of the shaded region). 


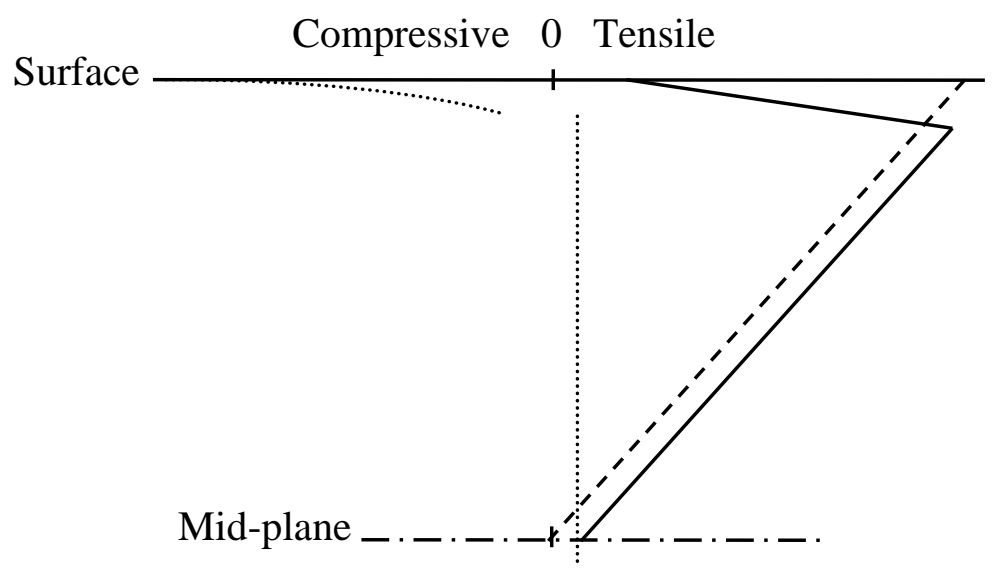

Fig.7a. Schematic showing the quasi-static stress distribution in a short exchange time sample: the dotted line is the residual stress profile imparted by the ion-exchange with maximum compression at the surface, the dashed line is bending load distribution, and the solid line is the resultant.

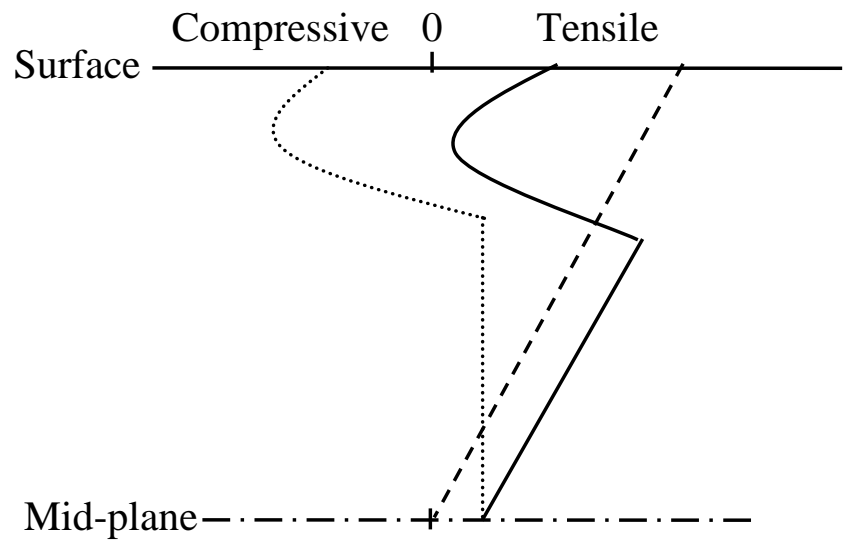

Fig. 7b. Quasi-static stress distribution in a long exchange time sample, with same notations as in (a). Note that the bending load is lower in this case and the resultant stress could drop close to zero below the surface, due to shift in the maxima in the residual profile. 
Fig 1a. Loads causing cracking and fragmentation when failure occurs during loading for various exchange times. The individual data points and average values (filled circles) for each exchange time are shown.

Fig $1 \mathrm{~b}$ Time until fragmentation occurred after unloading as a function of maximum load. The data points at time $=0$ indicate that cracking occurred during unloading.

Fig. 2 Montage of images showing the fracture surface for a $24 \mathrm{hr}$., $450^{\circ} \mathrm{C}$ sample loaded monotonically to fracture. Bottom left is the fracture origin. The crack pops-in, propagates through the thickness, and then sweeps through the sample, from left to right. The black dashed line marks the beginning of the first hackle.

Fig. 3: Fragmentation patterns for $1.8 \mathrm{~mm}$ thickness disks, exchanged for different times at different temperatures. All disk diameters are $25.4 \mathrm{~mm}$, and full disk images are shown. (a) $3 \mathrm{hrs}$., $500^{\circ} \mathrm{C}$, Tension $=37 \mathrm{MPa}$, (b) $6 \mathrm{hrs}$, $500^{\circ} \mathrm{C}, 45 \mathrm{MPa}$ (c) $12 \mathrm{hrs}$., $500^{\circ} \mathrm{C}, 55 \mathrm{MPa}$, (d) 24 hrs., $500^{\circ} \mathrm{C}$. $75 \mathrm{MPa}$, (e) 48 hrs., $500^{\circ} \mathrm{C}, 107 \mathrm{MPa}$, (f) 96 hrs., $500^{\circ} \mathrm{C}, 140 \mathrm{MPa}$, and (g) $12 \mathrm{hrs} .450^{\circ} \mathrm{C}, 37 \mathrm{MPa}$. Indentation loads varied, and fracture occurred during or after unloading.

Fig. 4 Strength of samples of two thicknesses for two exchange temperatures. the strength decreases with increasing exchange time due to surface stress relaxation. The boxed region is the range of strength for base glass samples.

Fig 5 The top-views of $1.8 \mathrm{~mm}$ thick samples exchanged at $500^{\circ} \mathrm{C}$, and fractured in biaxial flexure, for several exchange times are shown in Fig. 5a-g. (a) 3 hr. ex., Strength=681 MPa, (b) 24 hr. ex., Strength=588 MPa, (c) 96 hr. ex., Strength=446 MPa, (d) Magnified view of the $3 \mathrm{hr}$. exchange sample. Crack origin at (a), first branching at (b). (c) marks some of the regions where "tertiary" cracks are seen, (e) Magnified view of the $96 \mathrm{hr}$. exchange sample. Crack origin at (a), first branching at (b). (c) marks some of the regions where "tertiary" cracks are seen, and (f) Magnified view of $144 \mathrm{hr}$. exchange sample. The initial crack has a large number of branches, and the incidence of "tertiary" cracking is minimal.

Fig.6a. Schematic showing the spherical co-ordinate system centered at the initial point of contact of the conical indenter with the sample surface. The triangular region is the hardness impression, and the plastic zone has the radius a. All cracking is assumed to initiate at the edges of this zone, either on the surface (radial) or in the bulk (median). The shaded region is the zone of compression for short exchange times, with maximum stress at the surface. The compensating tension is below this region.

Fig. 6b. Schematic of a compression profile after significant relaxation has occurred: the compressive maximum has moved to a sub-surface location under the surface (darker portion of the shaded region).

Fig.7a. Schematic showing the quasi-static stress distribution in a short exchange time sample: the dotted line is the residual stress profile imparted by the ion-exchange with maximum compression at the surface, the dashed line is bending load distribution, and the solid line is the resultant.

Fig.7b. Quasi-static stress distribution in a long exchange time sample, with same notations as in (a). Note that the bending load is lower in this case and the resultant stress could drop close to zero below the surface due to shift in the maxima in the residual profile. 